\title{
Teaching The Interrelationships Among Costs, Expense, And Liability Of A Defined Benefit Pension Plan
}

Arlette C. Wilson, (Email: awilson@business.auburn.edu), Auburn University

Norman H. Godwin, (Email: godwin@business.auburn.edu), Auburn University

\begin{abstract}
The Financial Accounting Standards Board (FASB) recently issued Statement of Financial Accounting Standards No. 158 "Employers' Accounting for Defined Benefit Pension and Other Postretirement Plans" (SFAS \#158). Their intent is to comprehensively reconsider the accounting for postretirement benefit plans in phases. The first phase was to provide timely and significant improvements and resulted in SFAS \#158. The object of this Statement is to improve the understandability and representational faithfulness of the amounts reported in the employer's statement of financial position by recognizing as an asset or liability the overfunded or underfunded status of a defined benefit postretirement plan. The purpose of this paper is to provide a logical approach for teaching accounting for a defined benefit pension plan. This objective will be accomplished by providing a discussion with detailed illustrations of the interrelationships of the effects on income (both operating income and other comprehensive income) and the amount reported on the balance sheet.
\end{abstract}

\section{THE BIG PICTURE}

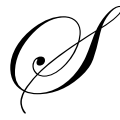

ometimes students get bogged down in the details and fail to see the big picture of what the accounting is trying to accomplish. The accounting for a defined benefit pension plan is now recognizing all costs (credits) and gains (losses) associated with the plan in either operating income or other comprehensive income (OCI), and the pension liability (asset) reported on the balance sheet will always be the underfunded (overfunded) projected benefit obligation (PBO).

Changes in all costs (credits) and gains (losses) will flow through either operating income via the Pension Expense or through $O C I$. The amounts included in Pension Expense will accumulate in Retained Earnings, while the amounts flowing through OCI will accumulate as accumulated other comprehensive income (AOCI) and will be reported as a separate component of stockholders' equity.

\section{ACCOUNTING FOR DEFINED BENEFIT PENSION PLANS}

The accounting for a defined benefit pension plan consists of three issues:

- $\quad$ Amounts to be recognized in current earnings via Pension Expense

- Amounts to be recognized in other comprehensive income and accumulated as a separate component of stockholders' equity

- $\quad$ Amount to be reported as Pension Asset or Liability

All costs (credits) and losses (gains) will flow through either current earnings or OCI resulting in a Pension Liability (Asset) on the balance sheet equal to the underfunded (overfunded) status of the plan. 


\section{Recognition In Current Earnings And OCI}

Exhibit 1 includes the actuarial report and trustee report for 2008. The total change in the company's PBO (less payments to retirees) and the actual return on plan assets is the total amount that should flow through either current earnings or OCI. Referring to Exhibit 1, that total change includes the following components:

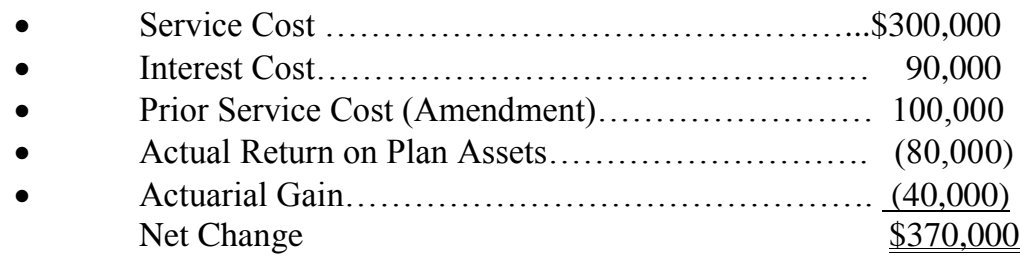

The actual return on plan assets and actuarial gain offset the costs associated with the plan because they represent revenues.

The amount that flows through current earnings via Pension Expense and the amount that flows through OCI are included in Exhibit 2. Below is an explanation of how each component of the net change in costs is included in either pension expense or OCI.

\section{Service Cost}

The service cost of $\$ 300,000$ for 2008 will be included in Pension Expense. So that entire amount will flow through current earnings.

\section{Interest Cost}

The interest cost of $\$ 90,000$ for 2008 will be included in Pension Expense. That entire amount will also flow through current earnings.

\section{Prior Service Cost}

The amendment to the plan caused the company's obligation to immediately increase by $\$ 100,000$. This is a real cost to the company, but the FASB chose to take a smoothing approach when calculating Pension Expense. Instead of recognizing the entire amount of prior service cost (PSC) in current earnings as incurred, a portion of that amount is included in Pension Expense over the average remaining service years. We chose to amortize this $\$ 100,000$ of prior service costs on a straight-line basis. Therefore $\$ 10,000(\$ 100,000 / 10$ years $)$ is included in Pension Expense for each of the next ten years. For 2008, $\$ 10,000$ of the $\$ 100,000$ flows through current earnings via Pension Expense. The other $\$ 90,000$ flows through OCI and accumulates in AOCI as a separate component of stockholders' equity. The creation of the PSC resulted in a decrease to OCI of $\$ 100,000$, but the $\$ 10,000$ amortization of PSC which was included in Pension Expense increased OCI.

\section{Actual Return On Plan Assets}

This amount is the return the trustee earned by investing the pension plan assets available at the beginning of the year. This amount should reduce Pension Expense and therefore increase current earnings. But because of the FASB's smoothing approach, they chose to include expected return on plan assets to be included in Pension Expense. Therefore, the difference between the Actual Return and Expected Return on Plan Assets must flow through OCI. When Actual Return is greater than (less than) Expected Return, the resulting gain (loss) will flow through OCI. The $\$ 20,000$ part of the $\$ 80,000$ actual return not reported in current earnings via Pension Expense for 2008 will increase OCI. 


\section{Actuarial Gain}

The actuary relies on several assumptions such as discount rate, years of employment and longevity to determine the PBO at any given time. If the actuary were to change any of these assumptions, then PBO would also change. A loss (gain) will result if the assumption change were to increase (decrease) PBO. The $\$ 40,000$ gain for 2008 is a real gain, but because the FASB chose the smoothing approach, this gain is not immediately included in current earnings. The $\$ 40,000$ gain will flow through OCI and accumulate in AOCI. The creation of this $\$ 40,000$ gain will increase OCI. The net loss or gain included in AOCI will flow out of OCI and into current earnings only if the net amount becomes too large as discussed below.

\section{Gain Or Loss Included In Pension Expense}

The smoothing approach for calculating Pension Expense results in two potential gains or losses as discussed above. Actuarial assumption change gains (losses) and the difference between actual and expected return on plan assets both result in amounts that do not flow through current earnings. When the net amount of gains or losses accumulated in AOCI become too large, then some of the gain or loss is included in current earnings via amortization of the gain or loss into Pension Expense.

The company had an unrecognized loss of $\$ 200,000$ at the beginning of 2008 . The threshold which determines if this loss is too large is $10 \%$ of beginning PBO or $10 \%$ of beginning fair value of plan assets, whichever is the larger amount. The larger amount is $\$ 150,000$ which is $10 \%$ of beginning PBO. Since the $\$ 200,000$ unrecognized loss is larger than this threshold, the $\$ 50,000$ excess $(\$ 200,000-\$ 150,000)$ is amortized to Pension Expense over the average remaining service period. Amortization of a loss (gain) will increase (decrease) Pension Expense. Therefore, $\$ 5,000$ (\$50,000/10 years) of the loss included in AOCI at the beginning of 2008 is removed from OCI and included in Pension Expense.

Removal of this $\$ 5,000$ loss from OCI increases OCI. Exhibit 3 summarizes how the creation of costs (credits) and losses (gains), as well as the subsequent amortization of these amounts into Pension Expense, affect OCI as they flow through.

\section{Pension Liability Or Asset}

Since all costs (credits) and losses (gains) are recognized in either current earnings or OCI, the Pension Liability (Asset) will reflect the underfunded (overfunded) status of the plan. That is, the difference between PBO and fair value of pension plan assets will be reported on the balance sheet as Pension Liability or Asset.

as:

Referring to the actuarial and trustee reports for 2008 in Exhibit 1, the Pension Liability should be reported

$\begin{array}{lr}\text { PBO, Jan.1 } & \$ 1,500,000 \\ \text { FVPA, Jan. 1 } & \underline{1,000,000} \\ \text { Pension Liability, Jan. 1 } & \underline{\$ 500,000} \\ \text { PBO, Dec. 31 } & \$ 1,670,000 \\ \text { FVPA, Dec. 31 } & \underline{1,090,000} \\ \text { Pension Liability, Dec. 1 } & \underline{\$ 580,000}\end{array}$

The change in the Pension Liability is the result of the following journal entries made for 2008:

$\begin{array}{lr}\text { (1) Dr. Pension Expense (Exhibit 2) } & \$ 345,000 \\ \text { Cr. Pension Liability } & 55,000 \\ \text { Cr. Cash (contributions Exhibit 1) } & 290,000\end{array}$


Dr. OCI (change in OCI, Exhibit 2) \$25,000

Cr. Pension Liability 25,000

Note that the amount that flows through Expense and OCI $(\$ 345,000+\$ 25,000)$ equals the $\$ 370,000$ net change for the year.

The Pension Liability account is updated as follows:

Pension Liability, Jan. 1, $2008 \quad \$ 500,000$

From journal entry (1) $\quad 55,000$

From journal entry (2) $\quad 25,000$

Pension Liability, Dec. 31, $1008 \quad \underline{\underline{\$ 580,000}}$

The unrecognized gain (loss) is updated as follows:

Unrecognized Loss, Jan. 1, 2008

Loss amoritization

$(\$ 200,000)$

Actual-Expected Return

5,000

Actuarial Gain

20,000

Unrecognized Loss Dec. 31, 2008

40,000

$\underline{(\$ 135,000)}$

The AOCI reported in stockholders' equity, which includes both unrecognized losses or gains and unrecognized prior service costs or credits, is updated as follows:

$\begin{array}{cc}\text { Accumulated OCI, Jan. 1, 2008 } & (\$ 200,000) \\ \text { Loss amortization } & 5,000 \\ \text { Actual-Expected Return } & 20,000 \\ \text { Actuarial Gain } & 40,000 \\ \text { Creation of Prior Service Cost } & (100,000) \\ \text { Amoritization of Prior Service Cost } & 10,000 \\ \text { Accumulated OCI, Dec. 31, 2008 } & \underline{(\$ 225,000)}\end{array}$

\section{Additional Illustration}

To reinforce the concepts just discussed, we'll continue the example for 2009. Exhibit 4 includes the actuarial and trustee reports, while Exhibit 5 provides the calculation of Pension Expense and the change in OCI. The total change in PBO (less payments to retirees) and the actual return on plan assets includes the following components:

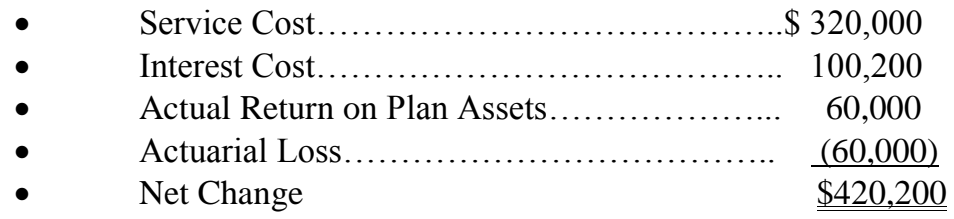

\section{Recognition In Current Earnings And OCI}

These changes flow through current earnings and OCI as indicated below.

Service Cost

The entire $\$ 320,000$ is included in current earnings for 2009 via Pension Expense. 
Interest Cost

The entire $\$ 100,200$ is included in current earnings for 2009 via Pension Expense.

Prior Service Cost

Only $\$ 10,000$ of the $\$ 100,000$ prior service costs arising in 2008 were included in 2008 current earnings. The other $\$ 90,000$ flowed through OCI and accumulated in AOCI. For $2009, \$ 10,000$ of the $\$ 90,000$ unrecognized prior service cost is removed from AOCI and included in 2009 current earnings via Pension Expense. Removal of this cost from AOCI will increase OCI. The net effect is to increase OCI and decrease current earnings.

\section{Actual Return On Plan Assets}

The actual return on plan assets for 2009 was $\$ 60,000$ while the expected return was $\$ 65,400$ (6\% of $\$ 1,090,000)$. The expected return increases current earnings via a reduction of pension expense. But since the actual return was less, the difference represents the loss that will flow through OCI.

Actuarial Loss

Actuarial assumption changes caused PBO to increase, resulting in a loss for 2009. This loss flows through OCI and accumulates in AOCI.

Gain Or Loss Included In Pension Expense

To determine if the unrecognized net loss (or gain) is too large, we'll compare the beginning of the year net loss of $\$ 135,000$ (calculated earlier for December 31,2008$)$ to $10 \%$ of the larger of beginning PBO $(\$ 1,670,000)$ or beginning FV Plan Assets $(\$ 1,090,000)$. The unrecognized net loss of $\$ 135,000$ is less than the threshold of $\$ 167,000$. Therefore, the unrecognized net loss does not need to be amortized as a component of Pension Expense.

\section{Pension Liability}

Referring to the actuarial and trustee reports for 2009 in Exhibit 4, the Pension Liability at December 31, 2009 should be reported as:

PBO, Dec. 31, 2009

FVPA, Dec. 31, 2009.

Pension Liability, Dec. 31, 2009
$\$ 1,860,200$

$1,180,000$

$\underline{\$ 680,200}$

The change in the Pension Liability is the result of the following journal entries made for 2009:

(1)
Dr. Pension Expense (Exhibit 5)
Cr. Pension Liability
$\$ 364,800$
44,800
Cr. Cash (contributions Exhibit 4)
320,000
Cr. Pension Liability
$\$ 55,400$ 55,400

(2) Dr. OCI (change in OCI Exhibit 5)

Note that the amount that flows through Expense and OCI $(\$ 364,800+\$ 55,400)$ equals the $\$ 420,200$ net change for the year. 
The Pension Liability account is updated as follows:

Pension Liability, Dec. 31, 2008

From journal entry (1)

$\$ 580,000$

From journal entry (2)

44,800

55,400

Pension Liability, Dec. 31, 2009

$\$ 680,200$

The unrecognized gain (loss) is updated as follows:

Unrecognized Loss, Dec. 31, 2008

Actual-Expected Return

$(\$ 135,000)$

Actuarial Loss

$(60,000)$

Unrecognized Loss, Dec. 31, 2009

$\$ 200,400$

The AOCI reported in stockholders' equity, which includes both unrecognized gains or losses and unrecognized prior service costs, is updated as follows:

$\begin{array}{cc}\text { Accumulated OCI, Dec. 31, 2008 } & (\$ 225,000) \\ \text { Amortization PSC } & 10,000 \\ \text { Actual-Expected Return } & (5,400) \\ \text { Actuarial Loss } & (60,000) \\ \text { Accumulated OCI, Dec. 31, 2009 } & \underline{\$ 280,400}\end{array}$

This AOCI is reported as a separate component of stockholders equity at December 31, 2009 and includes:

Unrecognized PSC

$(\$ 80,000)$

Unrecognized loss.

$(200,400)$

Total AOCI

$\underline{(\$ 280,400)}$

\section{SUMMARY}

The issuance of SFAS \#158, which requires all defined benefit pension plan costs (credits) and losses (gains) to flow through either current earnings or other comprehensive income, results in a pension liability (asset) that truly reflects the underfunded (overfunded) status of the plan.

Pension expense continues to be calculated as required by SFAS \#87. But now the unrecognized items which were previously reported as footnote disclosures will flow through OCI and accumulate as a separate component of stockholders' equity. This recognition of all costs (credits) and losses (gains) in either current earnings or OCI results in the Pension Liability (Asset) being reported as the amount by which project benefit obligation is greater than (less than) the fair value of the pension plan assets. Students should be shown the interrelationship between the pension plan costs and the amounts reported as expense, OCI, and liability.

\section{EXHIBIT 1}

\section{Actuarial Report And Trustee Report 2008}

\section{$\underline{\text { Actuarial Report }}$}

PBO, January 1

Service Cost

Interest Cost (5\%)

Plan Amendment

Payments

Actuarial Loss (Gain)

PBO, December 31

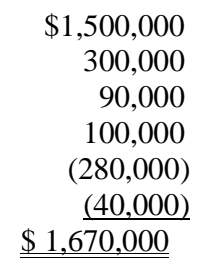

\section{$\underline{\text { Trustee Report }}$}

$\begin{array}{lr}\text { FV Plan Assets, Jan. } 1 & \$ 1,000,000 \\ \text { Contributions } & 290,000 \\ \text { Payments } & (280,000) \\ \text { Actual Return } & 80,000 \\ \text { FV Plan Assets, Dec. 31 } & \underline{\$ 1,090,000}\end{array}$




\section{EXHIBIT 2}

\section{Calculation Of Pension Expense And Change In OCI 2008}

\begin{tabular}{lc} 
& \multicolumn{2}{c}{ Pension Expense: } \\
\hline Service Cost & $\$ 300,000$ \\
Interest Cost & 90,000 \\
Expected Return on Plan Assets & $(60,000)$ \\
Amortization of Prior Service Cost & 10,000 \\
Amortization of Loss & 5,000 \\
Total Pension Expense & $\underline{\$ 345,000}$ \\
& Change in OCI: \\
\hline Prior Service Cost (PSC) & $(100,000)$ \\
PSC Amortization & 10,000 \\
Actual-Expected Return & 20,000 \\
Actuarial Gain & 40,000 \\
Loss Amortization & 5,000 \\
Total Change in OCI & $\underline{(\$ 25,000)}$
\end{tabular}

\section{EXHIBIT 3}

Effect Of Changes In Unrecognized Amounts On Other Comprehensive Income

\begin{tabular}{lll}
\hline & Created & Amortized \\
\hline Prior Service Cost & decrease & increase \\
Loss & decrease & increase \\
Gain & increase & decrease
\end{tabular}

EXHIBIT 4

Actuarial Report And Trustee Report 2009

\begin{tabular}{lclc}
\multicolumn{2}{c}{ Actuarial Report } & \multicolumn{2}{c}{ Trustee Report } \\
\hline PBO, Jan. 1 & $\$ 1,670,000$ & FV Plan Assets, Jan. 1 & $\$ 1,090,000$ \\
Service Cost & 320,000 & Contributions & 320,000 \\
Interest Cost (6\%) & 100,200 & Payments & $(290,000)$ \\
Plan Amendment & 0 & Actual Return & $\underline{60,000}$ \\
Payments & $(290,000)$ & FV Plan Asset, Dec. 31 & $\underline{\$ 1,180,000}$ \\
Actuarial Loss & 60,000 & & \\
PBO, Dec. 31 & $\underline{\$ 1,860,200}$ & &
\end{tabular}




\section{EXHIBIT 5}

\section{Calculation Of Pension Expense And Change In OCI 2009}

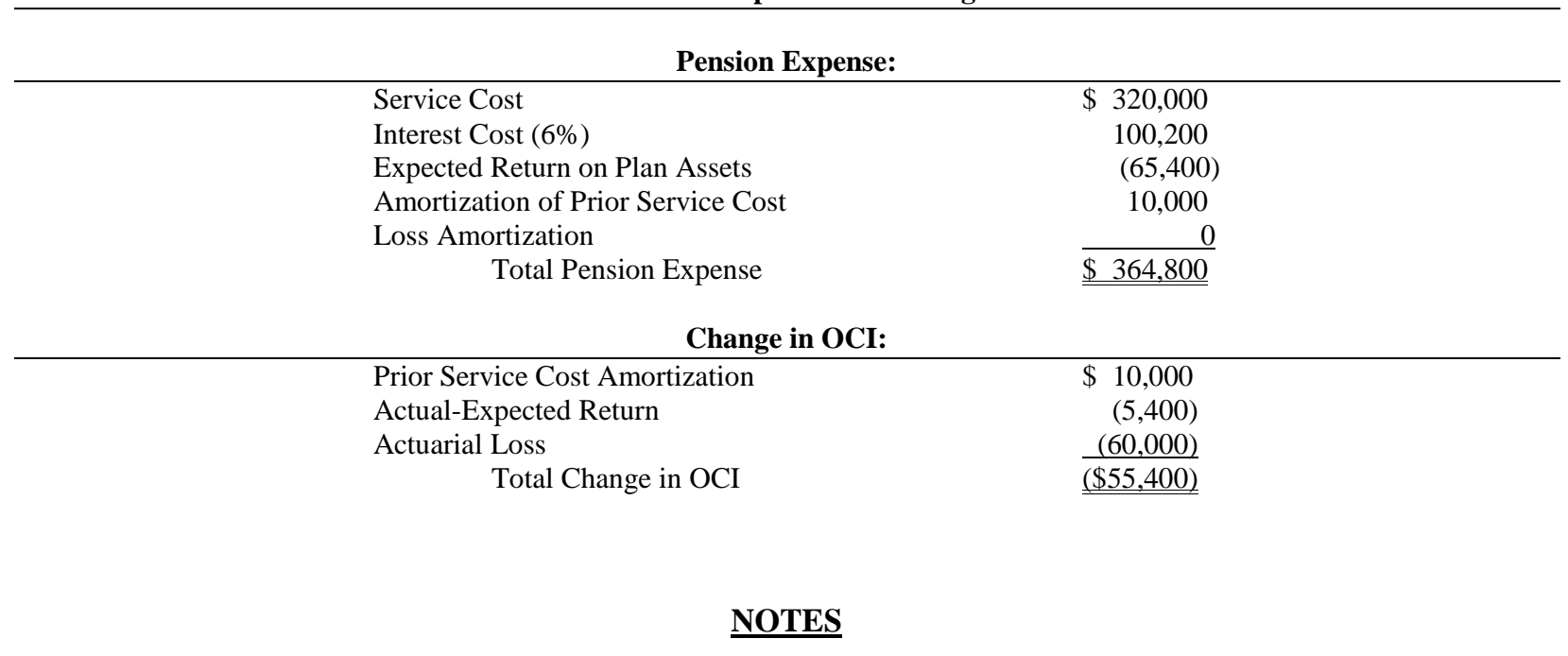

